\title{
Estudo experimental de leitura de uma bula de medicamentos, transcrita para o Sistema Braille, por usuários portadores de cegueira
}

\author{
Experimental study reading of medicine package insert, for Braille System transcript, \\ to the blind users
}

\begin{abstract}
Design da Informação, medicamentos, Sistema Braille, usuário cego, acessibilidade
Nesse artigo é descrito um estudo experimental realizado com usuários portadores de cegueira. Estes fizeram a leitura de uma bula de medicamentos transcrita para o Sistema Braille. Para tanto foi desenvolvido uma entrevista com a aplicação do modelo de apresentação gráfica de Karel van der Waarde. O objetivo desse estudo experimental foi o de avaliar a bula em suas características gráficas e informacionais para o usuário cego.
\end{abstract}

\section{Information Design, medicines, Braille System, blind user, accessibility}

This paper pretends the description of an experimental study realized with blind users. They read the transcription of the insert to the Braille System. For that reading did develop an interview with the Karel van der Waarde framework of graphic presentation application. The objective is the evaluation of the medicine package insert in to the graphic and informational characteristics for blind people users.

\section{Introdução}

Diversos estudos têm como foco o design de bulas de medicamentos no que se refere à sua estrutura gráfica e informacional. Através desses estudos foi possível definir e descrever problemas gráficos e informacionais nas bulas para videntes. Segundo Waarde (1999) as bulas, normalmente, são impressas com letras pequenas, em papel transparente, o que dificulta a leitura pelo usuário do documento. Ainda, segundo Cossío (2005) a presença de termos técnicos dificulta a compreensão pelo usário. Sless (2004) diz que documentos em geral têm sido deselegantes e o usuário os tem classificado como feios e difíceis de ler.

Karel van der Waarde (1999) desenvolveu um modelo descritivo sobre a apresentação gráfica de bulas de medicamentos, com a intenção de auxiliar o designer a desenvolver bulas mais eficazes no sentido gráfico e informacional. No entanto, seu modelo foi desenvolvido a partir de usuários videntes e nesse estudo o foco é sobre o usuário portador de deficiência visual.

No Brasil, há a legislação que especifica como as bulas devem ser em seu conteúdo informacional e em que seqüência esse conteúdo deve ser apresentado ${ }^{1}$. A Lei de Acessibilidade ${ }^{2}$ brasileira obriga a indústria farmacêutica a fornecer bulas aos deficientes visuais, "(...) mediante solicitação, (...) em meio magnético, Braille, ou em fonte ampliada". ${ }^{3}$ Assim, o acesso à bula em Braille é um direito garantido por lei no Brasil.

Segundo Lopes (2008) o que se verifica no dia-a-dia do usuário deficiente visual é que este enfrenta muitas dificuldades para ter acesso às informações sobre um medicamento prescrito, o que afeta sua autonomia como cidadão. Essas dificuldades são: receber a prescrição por escrito através de informações visuais na receita médica, na bula, e/ou na embalagem; a necessidade de ter uma pessoa, normalmente um parente ou um conhecido, que leia as informações para ele; na farmácia, no momento da dispensação, ele depende do farmacêutico para a confirmação das informações da receita médica; quando há informações em Braille na embalagem, estas são mínimas (nome comercial do fármaco e sua quantidade dentro daquela embalagem); as informações, quase totalmente, são transmitidas de forma oral, o que obriga o

\footnotetext{
${ }^{1}$ Portaria no 110, de 10 de março de 1997. Disponível em: HTTP://www.anvisa.gov.br/legis/portarias/110_97.htm

${ }^{2}$ Decreto n 5296 de 2 de dezembro de 2004, disponível em: HTTP://www.acessobrasil.org.br

${ }^{3}$ Idem citação 2
} 
paciente a memorizá-las para o posterior uso do remédio; a necessidade de confiar que as informações transmitidas tenham sido interpretadas da maneira correta por quem as leu para o deficiente visual.

Pela transcrição de uma bula de medicamentos para videntes é possível desenvolver uma bula no sistema de escrita direcionado a cegos, o Sistema Braille. No entanto é necessário que a bula seja avaliada com a intenção de otimizá-la no que se refere a sua estrutura gráfica e informacional. Assim sendo, uma leitura desta bula pelo usuário é essencial para que se definam suas necessidades relativas ao documento.

Nesse artigo se descreve um estudo experimental desenvolvido a partir de uma bula transcrita para o Sistema Braille, no qual se realizou sua leitura por usuários portadores de cegueira.

\section{O design de documentos para bulas}

A área do design de documentos tem explorado como, a escrita de documentos e uma boa comunicação visual podem melhorar a sua leitura efetiva. Neste sentido, o papel do designer não é fácil e as dificuldades oriundas do uso de documentos e suas complexidades gráficas/informacionais só serão superadas com o auxílio de uma fundamentação científica para o design de documentos (Schriver, 1997).

Sobre a escrita de documentos técnicos, Wright (1999) enfatiza que esta demanda habilidade verbal e de retórica de comunicação, destacando ainda elementos que influenciam sua eficácia comunicacional, a ver: o design tipográfico e de layout da página; a qualidade e estilo de ilustração; a administração do processo de desenvolvimento do documento (de sua concepção à veiculação); e freqüentemente a gerência de um grupo de escritores com funções técnicas distintas na produção do texto. Apesar de todos os aspectos técnicos envolvidos na produção de documentos, apenas a presença de profissionais especializados não garante o sucesso da comunicação. Assim, testes de usabilidade de documentos com seus usuários se fazem necessários, defende a autora. Ainda segundo Wright (1999) é através de uma abordagem participativa (entre designers, clientes, usuários) que o design pode ser desenvolvido como disciplina para a ciência. $O$ design inclusivo - que considera usuários com necessidades especiais - também deve ser uma preocupação do designer, que deve estar cada vez mais atento à necessidade de auxiliar pessoas com deficiências sensórias e cognitivas no entendimento das informações (Wright, 2003). Neste artigo isto será da maior relevância, pois o usuário em questão tem necessidades específicas relativas ao documento bula de medicamento, em se tratando do sistema de escrita Braille.

No Brasil o conteúdo das bulas é regulamentado pelo Ministério da Saúde, através da ANVISA (Agência Nacional de Vigilância Sanitária) pela portaria $n^{\circ} 110$. Mas, segundo Fujita e Spinillo (2006):

"é omissa no que se refere à apresentação gráfica das informações obrigatórias, assim, aspectos como legibilidade, clareza nas instruções visuais, layout do documento são desconsiderados, apesar da relevância destes aspectos na leitura e compreensão da mensagem. Problemas na composição gráfica de um documento como a bula, podem interferir no status hierárquico da apresentação dos elementos informacionais, caso estes possuam grau de semelhança na disposição tipográfica. No caso de bulas a apresentação de diferentes tipos de informação, como advertências e tabelas, fazem da bula um documento de considerável complexidade informacional e gráfica". (Fujita \& Spinillo, 2006)

É importante ainda considerar a simplificação da linguagem, a organização do conteúdo, os cuidados com a apresentação gráfica e a tipografia, e que se reduzam os movimentos que o leitor precise fazer para encontrar a informação (Cossío, 2005).

No que tange a leitura de bulas por usuários deficientes visuais ou cegos, Jones (2005) destaca que a impossibilidade de ler a bulas de medicamentos é um sério risco para a saúde dos mesmos. Segundo a autora o acesso a informação sobre os medicamentos é um direito básico e particularmente importante para as pessoas com deficiência visual.

Nesse estudo foi utilizado o modelo descritivo de Karel van der Waarde (1999) para a análise da bula transcrita para o Braille, portanto maiores explicações sobre o modelo serão feitas a seguir.

\subsection{O modelo de Karel van der Waarde}

Waarde (1999) apresenta três níveis de análise em seu modelo: 1. Componentes gráficos, 2. Relações entre componentes gráficos, e 3 . Apresentação gráfica global (figura 1). 
Figura 1. Modelo descritivo de Waarde (1999)

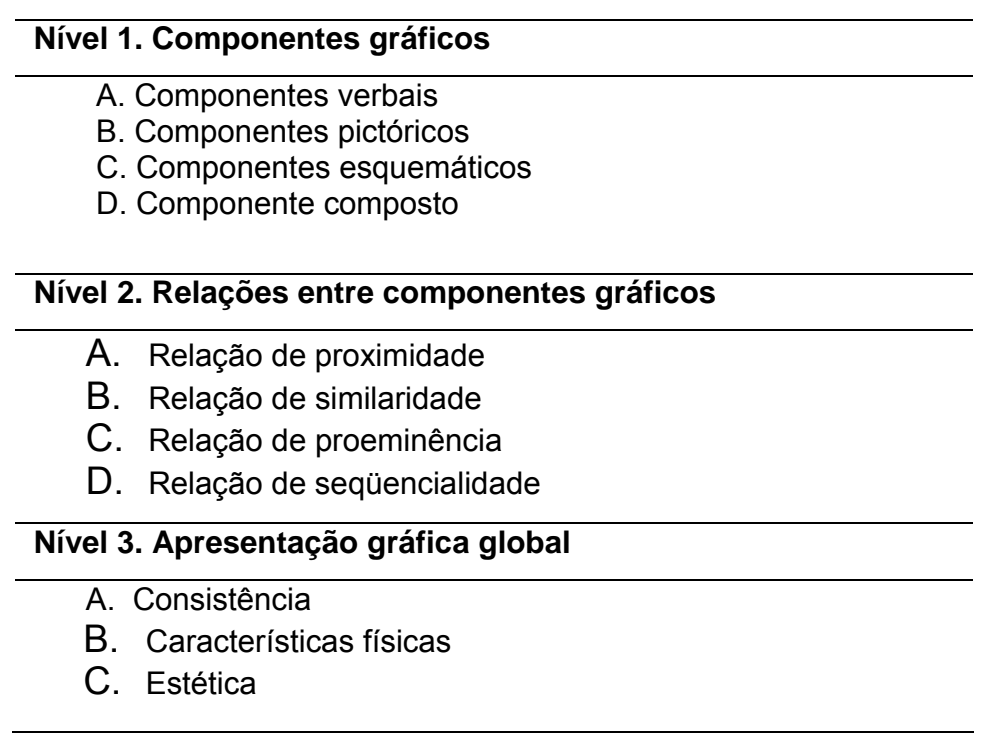

Os componentes verbais são definidos como marcas significativas que podem ser pronunciadas. Os componentes pictóricos são as marcas gráficas, ou grupo de marcas que relatam a aparência ou estrutura do objeto real ou imaginado (Twyman, 1985 apud Waarde, 1999). Os componentes esquemáticos não podem ser categorizados como pictóricos ou verbais. Um componente composto é uma configuração de marcas gráficas que não podem ser separadas, mas podem consistir em uma combinação de componentes verbal, pictórico e esquemático. Segundo Waarde (1999) estes três tipos de componentes são suficientes para uma descrição inicial dos objetos gráficos em bulas.

Sobre as relações entre componentes, em um segundo nível, a proximidade refere-se à distância entre os componentes gráficos. A segunda relação entre os componentes gráficos é a relação de similaridade. Os componentes gráficos visualmente diferentes apresentam diferentes elementos informacionais com status diferentes. A terceira relação pode ser descrita como uma relação de proeminência. A proeminência entre diferentes componentes gráficos é uma indicação de um conjunto de diferenças no status hierárquico entre os elementos informacionais. A quarta relação é a de seqüencialidade. A seqüência de componentes gráficos indica a sucessão de elementos informacionais.

As características da apresentação gráfica global são importantes segundo Waarde (1999) porque provêem o leitor com a primeira impressão do conteúdo informacional de uma bula. A primeira característica é a consistência da aplicação das variáveis gráficas em um documento. Um uso consistente dos componentes gráficos e as relações entre os componentes em toda a bula podem fazer com que a informação seja mais fácil de reter. Uma segunda característica é a estrutura física do documento. Por exemplo, as dimensões do documento, a qualidade do papel, tintas de impressão, a transparência, e reflexos. A última característica relatada sobre a apresentação é sobre o aspecto gráfico das bulas. Estes aspectos são os mais difíceis de descrever, mas eles são mencionados com maior freqüência em relação à apresentação gráfica.

Componentes referentes exclusivamente à percepção visual não farão parte do design desta bula, pois, não constam da bula transcrita. Aspectos relativos a adequações para o Braille e adaptações do modelo serão avaliados nas próximas etapas deste trabalho.

Mesmo sendo direcionado a bulas para videntes, o modelo de Waarde, é considerado o mais apropriado para o estudo, pois, trata o tema do design de bulas de forma completa e sistematizada. É importante lembrar que o modelo foi desenvolvido para o design de bulas, mas, pode perfeitamente ser utilizado no design de outros materiais.

Para uma melhor compreensão das características de documentos em Braille, no tópico a seguir, serão descritas, em linhas gerais, as normas para a aplicação do Sistema no Brasil, e também serão fornecidos exemplos de seu uso.

\section{O sistema Braille: conceituação, normas e exemplos de uso}

O Sistema Braille é composto por matrizes constituídas de seis pontos, dispostos em duas colunas de três pontos. A partir desta matriz chamada de cela, constituíram-se sessenta e quatro sinais (figura 2). A numeração da cela Braille, também chamado de sinal fundamental, se faz de 
cima para baixo, da esquerda para a direita (figura 3). Na figura 4 se pode verificar o alfabeto Braille:

Figura 2. Sinal fundamental do Braille(a) e cela vazia(b) em tamanho real.

\section{$\because:$}

Figura 3: Pontos do Braille e a direção de leitura na transcrição para a escrita convencional.

$$
\begin{aligned}
& \text { Sinal fundamental } \leftrightarrow \begin{array}{ll}
0 & 0 \\
0 & 0 \\
0 & 0
\end{array} \quad \leftrightarrow\left[\begin{array}{ll}
\downarrow & 4 \\
2 & 5 \\
3 & 6
\end{array} \mid\right. \\
& \uparrow \\
& \text { cela direção de escrita } \\
& \text { cheia dospontos }
\end{aligned}
$$

Figura 4: Alfabeto Braille

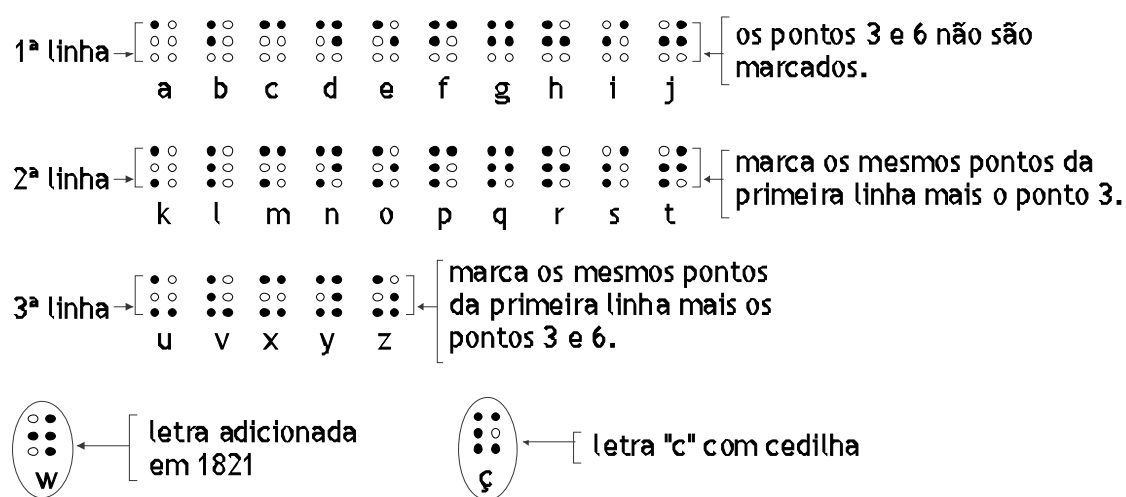

O sistema apresenta sinais de pontuação e sinais exclusivos, assim como a cela que acompanha a letra para a representação de fontes em caixa alta (figura 5). A representação de datas é feita de formas diferenciadas, com a seqüência de dia, mês e ano com os dias e mês em dois algarismos e o ano podendo ser com dois ou quatro algarismos, ou celas (figura 6).

Figura 5: Utilização do sinal de maiúsculas de acordo com a sua função no texto.

$$
\begin{aligned}
& \left.\begin{array}{l}
\bullet \\
\vdots
\end{array}\right] \text { sinal }(46) \quad \cdots \\
& \left.\begin{array}{cc}
: & 0 \\
0 & 0
\end{array}\right] \text { - letra "A" (46 1) }
\end{aligned}
$$

Figura 6. Representação de datas

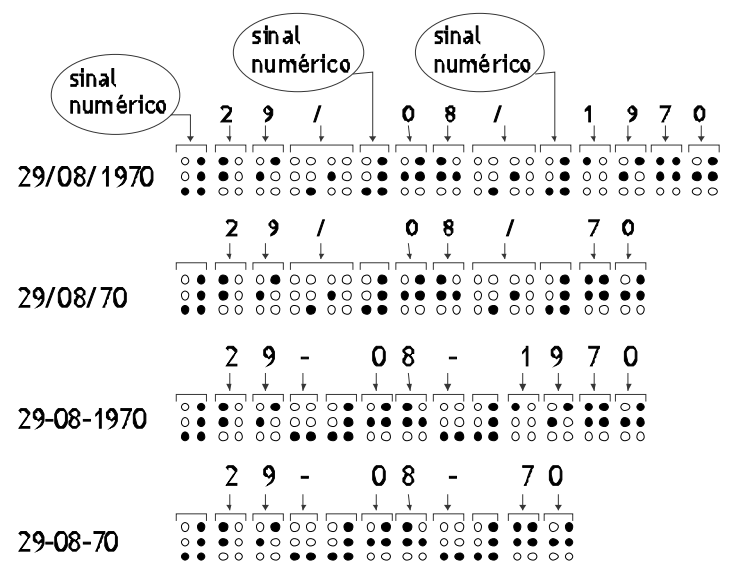


A leitura do Braille se dá da esquerda para a direita e o leitor deve prestar muita atenção para não saltar linhas, o reconhecimento geral dos símbolos Braille é feito com a mão direita, e a compreensão e leitura com a mão esquerda (Grifin e Gerber, 2003).

\subsection{Exemplos de uso do Braille e afins (verbal, pictórico e esquemático)}

No intuito de mostrar a diversidade representacional de materiais produzidos para o público de cegos/deficientes visuais, são apresentados aqui alguns exemplos de documentos, oriundos de um levantamento realizado junto a instituições de ensino e de apoio a este público, como também em bibliotecas.

O componente verbal (palavras e números) é o mais utilizado em documentos para cegos/deficientes visuais, sendo caixa-alta empregada como diferenciador entre títulos, subtítulos e textos corridos, verificados o uso extensivo deste recurso em documentos de fatura de água, nos livros didáticos e infantis, por exemplo. O agrupamento de blocos de texto se dá pelo espaçamento através de saltos de uma ou duas linhas e por endentações e recuos nos textos. uso de colunas também foi encontrado em livros didáticos e técnicos.

Já bullets (pontos maiores que os das celas) são empregados para marcação de tópicos de uso freqüente nas apostilas e livros de forma geral. Saltos de uma ou duas linhas para ênfase de partes do texto entre blocos e figuras, estão presentes tanto em livros didáticos e técnicos quanto em apostilas. O grifo é pouco utilizado nos livros e apostilas, sendo inexistente nos demais documentos. É freqüente o uso de tópicos com numeração, principalmente nos livros didáticos e apostilas.

Quanto aos componentes pictóricos, sua presença é comum em estórias infantis, como em figuras de personagens. É realizado através de agrupamentos de pontos formando linhas e áreas texturizadas, além de marcas gráficas como traços em baixo ou alto-relevo. $\mathrm{O}$ mesmo recurso é usado para diferenciar figura e fundo, com áreas preenchidas em contraste a áreas sem preenchimento (figura 7).

Figura 7. Representação em relevo de imagem

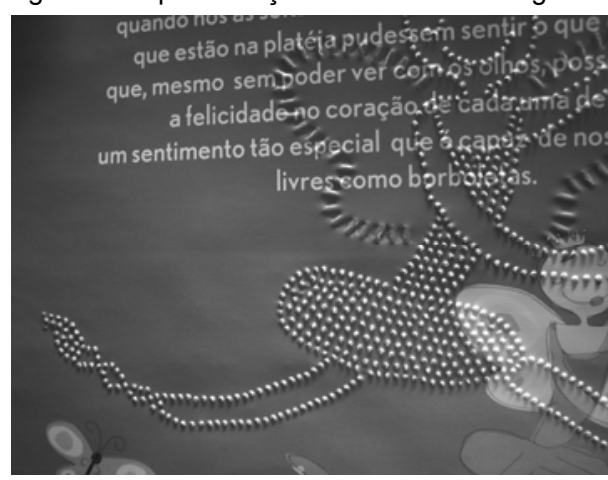

Figuras esquemáticas complexas como gráficos são freqüentes nos livros didáticos e são formadas por linhas pontilhadas, tracejadas, com diferenciações de tamanhos nos pontos e do distanciamento entre estes para ênfase em algumas áreas (figura 8). Os gráficos são apresentados em formas variadas como quadrangulares, retangulares, circulares e irregulares. Os quadros são comuns nos impressos formados, principalmente, por pontos consecutivos. Também estão presentes tabelas e ilustrações comentadas, assim como índices e sumários.

Figura 8. Representação em relevo de gráfico

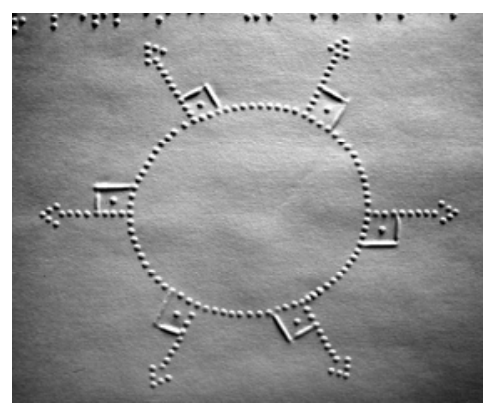




\subsection{Braille em embalagens e formulários}

Informações em Braille também se encontram presentes em embalagens de produtos comerciais, medicamentos e em formulários/faturas.

Em embalagens de alimentos, uma pequena extensão é destinada a informações em Braille, sendo que nestas tem-se o nome comercial do produto, o sabor e a quantidade. A impressão do Braille não chega a danificar as informações impressas para videntes, sendo quase imperceptíveis para estes. Em embalagens de barras de cereais, por exemplo, há informações como o nome comercial do produto, o sabor, o tipo (e.g. clássico ou light), a quantidade de barras.

Quanto ao uso do Braille em formulários/faturas, vale destacar como exemplo a conta de água no Estado do Paraná. Na conta impressa em Braille as informações foram reduzidas em relação àquelas veiculadas na conta para videntes, limitando-se aos dados do usuário, endereço e dados da Companhia de Saneamento do Paraná (Sanepar), as datas de leitura, o consumo, os valores dos serviços, o total, o vencimento da fatura. O impresso em Braille foi viabilizado em cumprimento ao Decreto 953/2007. A conta em Braille foi impressa em frente e verso, no sistema de interpontos e é impressa pela Imprensa Braille do Paraná.

Em embalagens de medicamentos alguns fabricantes apresentam informações como o nome comercial do medicamento e sua composição em miligramas ou mililitros. A bula de medicamento, entretanto, é disponível apenas para videntes acompanhando a embalagem. Há a possibilidade de acesso a bula em áudio através da solicitação pelos médicos, caso haja necessidade. Esse recurso, segundo Lopes (2008) é pouco conhecido dos pacientes com deficiência visual.

\section{Estudo experimental: a leitura da bula de medicamento em Braille}

O estudo experimental a seguir foi realizado com dois participantes portadores de cegueira, sendo que este é um estudo de caráter exploratório, fundamentado em dados qualitativos. O medicamento hidroclorotiazida foi selecionado a partir de entrevista realizada com médicos que atendem pacientes cegos internos em um Instituto em Curitiba, Paraná. A bula em Braille foi desenvolvida a partir do site da ANVISA ${ }^{4}$, seguindo as especificações da legislação vigente. $O$ uso do Sistema Braille segue normalização para a língua portuguesa estipulada pelo Instituto Nacional de Cegos $^{5}$, responsáveis pela fiscalização e normalização da escrita Braille no Brasil.

\subsection{Participantes}

Dois participantes do sexo masculino, com idade entre 45 e 65 anos, ambos com pós-graduação completa na área de Educação, portanto, com fluência em Braille.

\subsection{Material teste}

A bula analisada foi a do medicamento hidroclorotiazida, que é receitado para pacientes com hipertensão, ou, pressão alta. O conteúdo informacional para a transcrição foi extraído do bulário eletrônico da ANVISA ${ }^{6}$. Segundo solicitação do impressor da Imprensa Braille ${ }^{7}$ este texto foi salvo em formato "txt" (pelo bloco de notas do Word). A bula em "txt" resultou em nove páginas no formato A4 (210 X $297 \mathrm{~mm})$ com margem esquerda de $15 \mathrm{~mm}$, direita de $20 \mathrm{~mm}$, topo de $25 \mathrm{~mm}$, e base de $45 \mathrm{~mm}$. Esta bula foi impressa em papel sulfite com gramatura de 75 gramas.

$\mathrm{Na}$ impressão em Braille foi usado formulário contínuo $(260 \times 305 \mathrm{~mm})$ com papel na gramatura de 150 gramas, com margem de $4 \mathrm{~cm}$ à esquerda. Assim, o documento em Braille é composto por 38 páginas em papel liso, foi feita a impressão em frente e verso através da tecnologia de interpontos, ajuste que permite o deslocamento do texto para não ocorrer sobreposição dos pontos da frente com os do verso do documento.

Os próprios indicaram o local para fazer a leitura.

\footnotetext{
${ }^{4}$ http://anvisa.gov.br

${ }^{5}$ www.ibc.org.br

${ }^{6}$ http://bulario.bvs.br

${ }^{7}$ www.adevipar.hpg.org.br
} 


\section{Infodesıgn}

\subsection{Procedimentos}

Preliminarmente foram preenchidos os dados pessoais do participante, depois, a leitura da bula foi dividida em três partes:

Parte 1- Participante sem a bula de medicamentos em Braille;

Parte 2- Participante com a bula de medicamentos em Braille em mãos;

Parte 3- Solicitar que o participante encontre as informações indicadas.

Na parte 1 os leitores responderam questões sobre sua experiência com bulas de medicamentos. Como exemplo: onde buscam informações sobre um medicamento prescrito; de que forma recebem estas informações; quais informações mais lhes interessam; se já tiveram contato com bulas; se conhecem bulas em áudio.

Na parte 2 os participantes responderam questões específicas à estrutura gráfica da bula em Braille, com relação aos seus componentes gráficos, as relações entre esses componentes e sobre as características físicas da bula, a partir da leitura de trechos selecionados antecipadamente.

Na parte 3 os participantes fecharam a bula e foi solicitado que encontrassem informações específicas como, contra-indicações, reações adversas, interações medicamentosas, advertência e as indicações de armazenagem.

Ainda, foi solicitado que ambos classificassem a bula com relação à busca de informação, numa escala de 1 a 4 , em que 1= fácil, 2= a regular, 3= difícil, e, 4= a muito difícil. Também foi solicitado se teriam algo a acrescentar que Ihes parecesse relevante para o estudo e qual sua opinião sobre a bula que haviam acabado de ler, como satisfatória, regular ou ruim.

As entrevistas foram filmadas e gravadas em áudio para posterior transcrição. Assim, foram transcritas para a compilação dos resultados.

\section{Resultados e discussão}

A partir da leitura pelos participantes foi possível chegar aos resultados a seguir.

\subsection{Parte 1: Participante sem a bula de medicamentos}

Os dois participantes recebem informações sobre medicamentos oralmente, com parentes ou conhecidos. Ambos tiveram contato com a bula em tinta de forma oral.

Um dos participantes disse que as informações que mais lhe interessam nas bulas, em ordem crescente de interesse, são o uso do medicamento e os efeitos colaterais, o outro participante disse serem as contra-indicações e as reações adversas.

Os participantes demonstraram interesse no acesso a uma bula em Braille, sendo que um deles citou que seria interessante ter acesso também a outros documentos, citando manuais de instruções e cardápios em restaurantes. Os dois disseram que o acesso à bula em Braille pode ser por cadastramento.

Nenhum dos participantes tinha conhecimento da existência de uma bula em áudio.

\subsection{Parte 2: Participante com a bula de medicamentos em Braille em mãos}

Um dos participantes relatou que, com a bula em mãos, já começa a lê-la na primeira página e segue adiante na leitura. $\mathrm{O}$ outro participante com a bula em mãos disse que se tratava de uma "bulona" se referindo ao seu tamanho e quantidade de páginas.

\section{- Questões específicas: Nível 1 - Componentes gráficos verbais}

As letras em caixa-alta foram tidas como uma forma de destacar informações relevantes na bula, $\mathrm{e}$ que o sinal de caixa-alta é facilmente reconhecível fornecendo o destaque desejado. Um deles enfatizou que acredita que o uso da caixa-alta é para destacar algumas informações, sendo que, segundo ele, o leitor se concentraria mais nessas informações e as memorizaria melhor. Ambos disseram que as informações em caixa-alta, como estão, ficam bastante salientadas na bula. Nesta fase da leitura um participante leu informações em que somente a primeira letra estava em caixa-alta, palavras inteiras, ou, frases inteiras. Quando um dos participantes leu o trecho em que a informação "como o medicamento funciona?" e o "nome comercial do medicamento" em caixaalta, disse que o destaque era muito bom e que estavam idênticos sem diferenciações gráficas entre as duas informações.

Ao ler um trecho em que havia informações em caixa-alta e caixa-alta e baixa, um dos participantes identificou o uso de caixa-alta somente na primeira letra como forma de indicar o 
início de parágrafo. O uso de caixa-alta na palavra toda, ou na frase toda, foi reconhecido como indicação de títulos em todos os trechos que foram lidos.

- Questões específicas: Nível 2- Relações entre os componentes gráficos

- Proximidade

Nesta fase da leitura os participantes foram questionados sobre a proximidade dos elementos na bula. Portanto, sobre a padronização das entrelinhas, os saltos de uma ou mais linhas, recursos utilizados como forma de proporcionar a relação de proximidade entre as informações.

Um dos participantes comentou que a padronização da entrelinha fixa deixa o texto legível, e que o fato de estar impresso em frente e verso não atrapalhou a legibilidade do texto. Um dos leitores foi informado do significado do termo "entrelinha fixa", pois, não sabia do que se tratava.

Um leitor comentou também, que se o conteúdo deve ser destacado, deve apresentar espacejamento (salto de linhas) para proporcionar esse destaque, diferenciando assim, títulos de textos corridos, como foi feito no trecho lido por ele, saltando-se uma linha antes e após os títulos. Ele relatou, também, que o salto de linha foi utilizado para destacar algumas informações, como títulos. Identificou o salto de linhas em um trecho como sendo para a indicação de itens, onde não era o caso. Para ele, em todos os trechos lidos foi utilizado o salto de uma só linha e que isso era tido como satisfatório.

\section{- Similaridade}

Na bula em Braille foi utilizada a caixa-alta como uma forma de diferenciar informações, ou de proporcionar semelhança gráfica e informacional.

No primeiro trecho lido um dos participantes identificou frases em caixa-alta como títulos, que ficaram segundo ele, bem destacados dos textos corridos. Ele ainda comentou que ao fazer uma leitura aleatória, abrindo a bula e buscando a informação aleatoriamente, as informações em caixa-alta têm mais destaque que os textos em caixa-alta e baixa, ou seja, textos corridos.

Um dos participantes ressaltou que o salto de linhas foi utilizado para salientar informações, como títulos. Relatou ainda que títulos e outras informações, como advertências, estão com o mesmo destaque na bula toda.

Ao ser questionado sobre uma possível diferenciação entre títulos, advertências, um participante comentou que naquela bula, títulos e outras informações como advertências estavam graficamente idênticas, ambas em caixa-alta. Sugeriu ainda, que seria interessante grifar as informações que devem ter mais destaque, como as advertências, utilizando o sinal de grifo em conjunto com a caixa-alta. Que o sinal de grifo proporciona menor destaque que o sinal de caixaalta, portanto, ambos devem ser utilizados em conjunto. Sobre a possibilidade de se colocar uma linha embaixo da frase ou das palavras a se destacar, como uma forma de grifar a informação, o leitor disse que uma linha não proporcionaria o mesmo efeito do uso de caixa-alta com grifo. Segundo ele, ao se deparar com uma linha, simplesmente não daria importância àquela informação, e a saltaria, em suas palavras, 'sem qualquer intenção'.

O outro participante também relatou que não havia diferenciação entre títulos e advertências. Quando o participante leu uma advertência (crianças não devem utilizar este medicamento) disse que deveria ser pulado uma linha entre o título (advertências) e o texto (crianças não devem utilizar este medicamento) para diferenciar a natureza destas informações. Segundo ele as informações deveriam ser separadas com um salto de linha.

Disse que títulos eram bastante destacados do texto corrido, pois há pulo de linha, e constatou que os títulos estão em caixa-alta por completo. No trecho sobre as "indicações do medicamento" o leitor disse que seria interessante colocar a palavra indicações em caixa-alta, como já está, mas também adicionar dois pontos após a palavra, e já colocar a frase hipertensão arterial sem pular linha, pois, segundo ele, não haveria perda de tempo na leitura.

Onde não há salto de linha entre um bloco de texto e outro, um leitor indicou que seria interessante que houvesse uma separação por um salto de linha, segundo ele, para destacar mais as informações durante a leitura.

Um dos participantes considerou que a advertência, sobre a proibição do uso do medicamento em crianças, deveria ser mais bem sinalizada. Esta informação surgiu após o título contra-indicações todo em caixa-alta, sendo que ele está toda em texto corrido, ou seja, caixa-alta e baixa. Ao ler uma advertência em caixa-alta e baixa (texto corrido) em comparação com um título todo em caixa-alta, o leitor relatou que a informação toda em caixa-alta era mais importante, inclusive o conteúdo. Ou seja, ele concluiu que o título era mais importante que a advertência.

Um dos participantes identificou erro de escrita na palavra beta-bloqueadores, pois, segundo ele, deve ser seguida a regra da escrita portuguesa em que deve haver um espaço entre beta- bloqueadores, o que dificulta a leitura. 


\section{Infodesıgn}

Um dos leitores disse que, na bula, os títulos poderiam começar mais à direita, pois, estes começam na altura do início dos parágrafos. Disse isso como forma de proporcionar melhoria estética no documento.

Ambos identificaram todos os textos em caixa-alta como títulos.

\section{- Seqüenciamento}

Na bula em Braille foi utilizado o recurso de hifenização para indicar itens, assim como o foi na bula em tinta.

Na leitura do primeiro trecho solicitado a um dos participantes, esse não conseguiu reconhecer os sinais de traços, dizendo que o traço estava muito confuso e que não sabia se era um hífen ou não. Disse que estava difícil de ler e que para ser mais fácil, poderiam ser colocados dois traços seguidos ao invés de somente um, antes da frase. Ao ser questionado se ao invés disso, se haveria melhoria na leitura, ao terminar a frase se fosse colocado um ponto e vírgula, o traço, e continuasse a frase, ao invés de pular linha antes de cada tópico. O participante disse que seria muito melhor, se fosse assim. Portanto, terminaria a frase, colocaria o ponto e vírgula e em seguida o traço, um espaço e a próxima frase. Disse que o traço no começo da frase torna-se de difícil reconhecimento e confuso. Não ilegível, porém, confuso.

O hífen entre as palavras foi reconhecido facilmente. Um dos participantes disse que não é pela legibilidade da impressão, mas, pela forma como foi usado o hífen podendo se tornar difícil de reconhecer. Enfatizou que entre as palavras não houve dificuldade para o reconhecimento e a leitura. Ao referir-se a um trecho em que havia novamente o salto de linha entre itens e o uso de hífen no início da próxima frase, em comparação com o hífen entre as palavras (e.g. duplo-cegos), o leitor indica que se façam todos contínuos, separados por ponto e vírgula e espaço. Assim, não haveria confusão com o traço de separação de palavras porque entre palavras o hífen é unido à palavra e nos itens o traço é separado por espaço.

O outro participante reconheceu os hífens de itens e também os separadores de palavras. Não houve confusão na leitura. Encontrou erros de grafia na escrita de palavras compostas, como beta-bloqueadores. Disse que há um espaço entre o hífen e bloqueadores. Em trecho em que surge a palavra placebo-controlados disse que a frase terminou com placebo, hífen, e na outra linha a palavra 'controlados'. Segundo ele deveria ser placebo, hífen, e na outra linha, hífen novamente e a palavra controlada. Da forma em que se encontra confunde-se com separação de sílabas e não como separação de palavras, como deveria ser.

\section{- Questões específicas: Nível 3 - Apresentação gráfica global - Consistência}

Para um dos participantes os títulos e textos corridos foram reconhecidos com facilidade.

Títulos e advertências foram tidos como idênticos em sua apresentação gráfica. Quando este participante leu trecho no qual o título contra-indicações, todo em caixa-alta; em seguida, sem salto de linha, toda em caixa-alta e baixa, a advertência; o leitor disse que o título era mais importante que o texto abaixo, ou seja, a advertência, pois, estava todo em caixa-alta. Comentou que a diferenciação estava ótima.

Um participante ressaltou que os títulos deveriam estar mais à direita, para salientá-los. Disse não haver, segundo ele, a necessidade de que estivessem no centro da página, mas, que o espaço de três caracteres para a direita seria o suficiente.

Ambos reconheceram um trecho da bula como itens em indicações, hipertensão arterial e contra-indicações, e não era o caso (figura $\mathrm{x}$ ).

\section{INDICAÇÕES}

Hipertensão arterial.

\section{CONTRA-INDICAÇÕES}

Choque cardiogênico, insuficiência cardíaca descompensada, bloqueio AV de II e III graus, bradicardia sinusal acentuada, anúria e hipersensibilidade aos componentes do produto ou a outras drogas derivadas da sulfonamida.

\section{MODO DE USAR E CUIDADOS DE CONSERVAÇÃO DEPOIS DE ABERTO}

O medicamento deve ser tomado, com um pouco de líquido, pela manhã.

Nenhum dos participantes reconheceu as advertências que estavam em caixa-alta e baixa (texto corrido) depois de um título (contra-indicações) todo em caixa-alta. 
CONTRA-INDICAÇÕES

Crianças não devem usar este medicamento.

Não use este medicamento se tiver choque de origem cardíaca, insuficiência cardíaca descompensada (incapacidade do organismo restabelecer o equilíbrio físico), alterado por um problema estrutural ou funcional, bloqueio de ramo, diminuição acentuada na freqüência cardíaca, interrupção na eliminação de urina ou alergia a qualquer um dos componentes ou a drogas derivadas da sulfonamida (tipo de droga com ação contra micróbios).

\section{Características físicas:}

- dimensões

Ambos consideraram que o formato da bula está satisfatório, assim como o comprimento das linhas e as margens. Também, os dois acreditam que o formato padronizado (ofício) que foi utilizado na bula, é mesmo o melhor.

\section{- impressão}

Ambos consideraram a qualidade de impressão satisfatória com relação ao relevo dos pontos Braille e o papel utilizado, sendo que o papel foi considerado excelente em sua gramatura. Um dos participantes relatou que com o tipo de encadernação em espiral associado àquele papel não havia qualquer dificuldade de leitura com relação ao manuseio e legibilidade.

Sobre a impressão em frente e verso ambos relataram que a qualidade da bula está ótima e que não há qualquer dificuldade de leitura.

\subsection{Parte 3: Busca de informações solicitadas pela pesquisadora}

Aqui os participantes fecharam a bula para buscar as informações solicitadas.

Participante 001: No momento em que foi solicitado que encontrasse a "indicação de armazenagem", este não encontrou, pois, na bula o título estava como "Armazenagem". 0 primeiro participante levou um minuto e oito segundos ("1'8”) para encontrar as contra-indicações, trinta segundos (30") para encontrar as advertências, cinco minutos e dois segundos ( $5^{\prime} 02$ ") para as interações medicamentosas, quarenta e um segundos (41") para as reações adversas e após um minuto e trinta e dois segundos (1'32") de busca desistiu de encontrar a indicação de armazenagem que estava com o título armazenagem.

A leitura teve duração de uma hora, cinqüenta e três minutos e dez segundos (1:53'10").

O participante 002 encontrou as contra-indicações em trinta e um segundos (31"), as reações adversas em dois minutos e vinte e cinco segundos (02'25"), as interações medicamentosas em doze segundos (12") dizendo que acreditava que já havia passado pela informação. Encontrou as advertências em dezessete segundos (17"), e a armazenagem, que foi solicitado para encontrar como estava escrito no texto, foi encontrada em um minuto e onze segundos (1'11"), quando o participante acreditou que não iria encontrar, pois, pensou que não era onde ele acreditava estar dizendo: "Fui para a frente e não era", logo em seguida "ah,era sim, página 37", encontrando a informação.

A leitura teve duração de 59'08" para o segundo leitor.

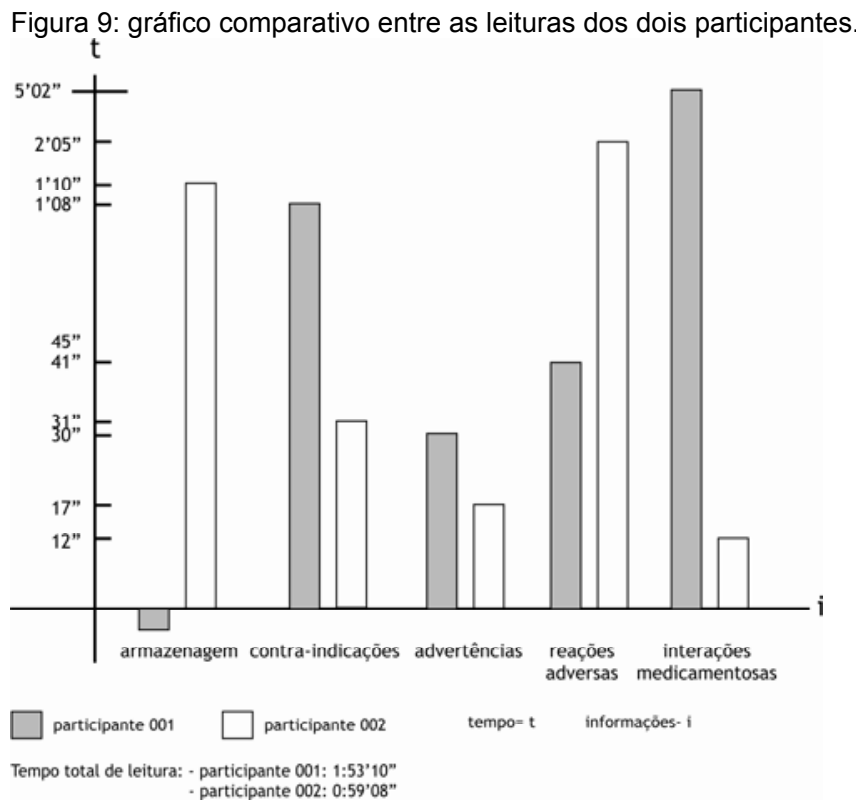


Ao serem solicitados que classificassem a bula com relação à busca de informação no texto em uma escala de 1 a 4, sendo que 1= fácil, 2= regular, 3= difícil, 4=muito difícil; ambos responderam que foi fácil (1). Comentaram sobre a importância da fluência em Braille para a facilidade da leitura.

Quando questionado se gostaria de acrescentar algo que the parecesse relevante para o estudo, um dos leitores solicitou que fosse retirado o endereço eletrônico da empresa que imprimiu a bula de todas as páginas.

Ambos consideraram a bula satisfatória.

Com relação à primeira parte da leitura da bula pode-se considerar que os participantes têm grande interesse no acesso a bulas em Braille, pois, atualmente só recebem informações oralmente ou com parentes e conhecidos.

Sobre os componentes verbais, os leitores consideraram que o uso de caixa-alta como forma de salientar informações é satisfatório, porém, apresentaram dificuldades de leitura, ocasionadas pelo uso desse recurso. Os textos em caixa-alta são facilmente percebidos durante a leitura. A forma como foi feito o uso de caixa-alta causou confusão na diferenciação de informações. Todos os textos (e.g. contra-indicações, modo de uso, advertências) foram apresentados com a mesma importância devido à sua apresentação em caixa-alta, o que causou problemas de hierarquia informacional da bula, sendo descritos como títulos e com a mesma importância de conteúdo.

Sobre as relações de entre os componentes gráficos a entrelinha fixa foi tida como uma forma de proporcionar proximidade no texto da bula. O salto de linhas também foi tido como forma de destacar trechos do texto, diferenciando-se assim, títulos de textos corridos. Em um trecho da bula os dois leitores confundiram textos com itens.

O uso da caixa-alta foi tido como uma forma de proporcionar relação de similaridade entre os elementos na bula em Braille. Porém, ambos relataram que informações de natureza diferente estão graficamente idênticas na bula, sendo que foi sugerido um destaque maior entre essas informações através do uso de grifo associado à caixa-alta. Os participantes não conseguiram identificar uma advertência na bula porque esta estava em texto corrido e após um título todo em caixa-alta. Também foi sugerido que se saltasse uma linha antes e depois da informação como uma maneira de destacá-la. Durante a leitura foram identificados erros de grafia de palavras compostas, com a presença de hífen. Segundo um dos leitores, uma forma de destacar melhor os títulos seria iniciando o parágrafo mais à direita na página.

$\mathrm{Na}$ bula toda a hifenização foi utilizada para atribuir a qualidade de itens o que causou dificuldade de reconhecimento do sinal para um dos leitores. Um participante detectou erros no uso de hífen para separar palavras.

Sobre a apresentação gráfica global da bula em Braille foi unânime a confusão entre a hierarquia informacional de títulos e advertências.

Com relação ás características físicas do documento, as dimensões (formato) foram consideradas satisfatórias e que é o melhor para esse tipo de documento. Sobre a impressão também não houve qualquer consideração contra o que foi apresentado, sendo que o documento foi considerado excelente em sua legibilidade e com relação ao manuseio, além da encadernação em espiral considerada ideal.

No momento da busca aleatória de informações houve dificuldade, apesar dos leitores relatarem que a leitura foi fácil, pois, ambos foram obrigados a percorrer a bula toda, página a página, para encontrar as informações solicitadas.

Um dos participantes não conseguiu encontrar a indicação de armazenagem do medicamento somente porque esta estava escrita diferente do que foi indicado pela entrevistadora. A diferença do tempo de conclusão da leitura foi de cinqüenta e três minutos e cinqüenta e dois segundos. Houve diferença de tempo de leitura para cada informação, sendo que em média o primeiro participante gastou mais tempo para a conclusão, com exceção da busca da informação 'reações adversas'.

\section{Conclusão}

Foi possível perceber que a bula em Braille pode ser otimizada através da aplicação do modelo descritivo de apresentação gráfica de Karel van der Waarde (1999), podendo aumentar a sua eficácia. A leitura da bula pelos participantes foi fundamental para detectar problemas de hierarquia informacional, como nos títulos e advertências. Também com relação a características da leitura e escrita do Braille como o caso onde se verificou a necessidade de se proporcionar destaque através de grifo com caixa-alta associados. 
O fato da bula em Braille ser composta por um grande número de páginas fez com que se pense em auxiliar o leitor com a adição de um sumário. A numeração por itens também pode auxiliar na busca da informação pelo leitor na bula. É possível destacar mais as advertências, diferenciando-as de títulos e outras informações, definindo assim, a hierarquia informacional na bula.

Outros recursos como saltos de linhas, linhas delimitadoras entre blocos de informações, podem ser aplicados para a otimização da bula, enfatizando assim a hierarquia informacional e auxiliar o usuário na leitura, tornando-a mais agradável.

Com a leitura pelo usuário foi possível observar a influência de fatores gráficos na eficácia da bula de medicamentos. Pretende-se assim, proporcionar uma bula que apresente qualidade de estrutura gráfica e informacional ao leitor do Braille.

\section{Referências bibliográficas}

BRASIL. IBGE (Org.) (2000). Censo Demográfico 2000. Disponível em: <http://www.ibge.gov.br/home/presidencia/noticias/27062003censo.shtm>. Acesso em abril de 2007.

BRASIL. Ministério da Saúde. Bula para o paciente. Disponível http://bulario.bvs.br/?action=saude.54154305200511\&phpsessid=91c00d8354b011596afb5 1e1e568dcc. Acesso em 13 de novembro de 2005.

BRASIL. Ministério da Saúde, 1997. Portaria n.110, de 10 de março de 1997. Disponível em: http://www.anvisa.gov.br/legis/portarias/110_97.html. Acesso em 20 de maio de 2007.

BRASIL(2004). Decreto $\mathrm{n}^{\circ}$ - 5.296, de 2 de dezembro de 2004. Lei de Acessibilidade. Disponível em: http://www.acessobrasil.org.br. Acesso em 10 de abril de 2007

COSSíO, Maria de González Del (2005). Information design for medicines in México. Palestra proferida no $2^{\circ}$ Congresso Internacional de Design da Informação. São Paulo: Senac / Sociedade Brasileira de Design da Informação.

FUJITA, Patrícia T.L; SPINILLO, Carla G. (2006). A apresentação gráfica de bula de medicamentos: um estudo sob a perspectiva da ergonomia informacional. In: Congresso Internacional de Ergonomia e Usabilidade 'ERGODESIGN'. Bauru. Anais. Bauru: UNESP, 2006. p.1-6. 1CD-ROM. ISBN: 85-99679-02-3.

GIL, Antônio Carlos (1999). Métodos e técnicas de pesquisa social. $5^{a}$ ed. São Paulo: Atlas.

GILL, Jonhn (2004-05). Braille labeling of medicines: meeting directive 2004/27/EC. RNIB. Disponível em: www.tiresias.org/guidelines/instruction books.htm Acesso em: 13 de abril de 2008.

GRIFFIN, Harold G.; GERBER, Paul J. Desenvolvimento tátil e suas implicações na educação de crianças cegas. Tradução de Ilza Viegas; revisão de Paulo felicíssimo e Vera Lúcia de Oliveira Vogel.

Guidelines regarding implementation of the European union directive on medicinal products for human use. Package information leaflets (or Patient Information Leaflets - PIL). (2000-07). Accessibility for Visually Impaired end-users. European Blind Union. Disponível em: http://www.euroblind.org/fichiersgb/pil-guid.htm Acesso em: 13 de abril de 2008.

JONES, Fiona. (2005). Medicine's blind spot. In: People in Life Sciences (P.I.L.S.). Disponivel em: http://www.honeycombonnect.com/ people_in_life_sciences(P.I.L.S.)/document_5325. ashx\%3fpage\%3dcompliance_column. Acesso em 10 de abril de 2007.

LOPES, M.O. (2008). Análise sobre o processo de obtenção e uso de medicamentos por pacientes com deficiência visual a partir de processo descrito por pacientes videntes. In: Anais do Seminário Design de Informação sobre Medicamentos, 2008.

RAYNOR, D.K. Head, YERASSIMOU, N. (1997). Medicines information-leaving blind people behind? Manufacturers should provide information in large print, Braille, or audiotape. In: BMJ: Helping doctors make better decisions. London. Disponível em: <http://www.bmj.com/cgi/content/full/315/7103/268. Acesso em 14 de abril de 2007. 


\section{Infodesıgn}

SILVA b, Tatiane da et al. (2000). Bulas de medicamentos e a informação adequada ao paciente. Rev. Saúde Pública, São Paulo, v. 34, n. 2. Disponível em: $<$ http://www.scielo.br/scielo.php?script=sci_arttext\&pid=S00348910200000000013\&lng=pt \&nrm=iso>. Acesso em: 21 de Abril de 2007. Pré-publicação.

SILVA, E.L.; MENEZES, E.M. (2000). Metodologia da pesquisa e elaboração da dissertação. Florianópolis: Laboratório de Ensino à Distância da UFSC.

SLESS, D. (2004). Designing public documents. In: Information Design Journal + Document Design 12 (1), p. 24-35.

VENTURINI, Jurema Lucy; ROSSI, Teresinha Fleury de Oliveira. (1995). Louis Braille: sua vida e seu sistema. Publicação da Fundação para o Livro do Cego no Brasil, $2^{\mathrm{a}}$ edição, São Paulo.

VAN DER WAARDE, Karel. (1999). The graphic presentation of patient package inserts. In: ZWAGA, Harm J.G.; BOERSEMA, Theo; HOONHOUT, Henriëtte. C.M. (Ed) Visual information for everyday use: Design and research perspectives. London, Taylor \& Francis. p.75-81.

Karel. (2004). Visual information about medicines. Providing patients with relevant information. SPINILLO, Carla G.; COUTINHO, Solange G. (Eds.). Selected Readings of the Information Design International Conference, 2003. Recife, SBDI - Sociedade Brasileira de Design da Informação. p.81-89.

WRIGHT, Patricia. (1999). Printed instructions: can research make a difference: In: ZWAGA, Harm J.G.; BOERSEMA, Theo; HOONHOUT, Henriëtte. C.M. (Ed) Visual information for everyday use: Design and research perspectives. London, Taylor \& Francis. p.45-66.

\section{Sobre os autores}

Maria Olinda Lopes, possui graduação em Artes Plásticas com habilitação em Gravura pela Escola de Música e Belas Artes do Paraná (1994) e também é Especialista em História da Arte (2003) pela mesma faculdade. Concluiu mestrado em Design pela Universidade Federal do Paraná (2009). Atua como Designer editorial e é professora universitária na área desde 2003. Atualmente leciona em instituição universitária particular em Curitiba, no curso de Comunicação com habilitação em Publicidade e Propaganda. Tem artigos publicados na área de Design da Informação e teve um destes premiado no Congresso Brasileiro de Pesquisa e Desenvolvimento em Design - P\&D Design 2008.

olindaart@hotmail.com

Carla G Spinillo. É bolsista produtividade do CNPq, docente da UFPR-Universidade Federal do Parana, e colaboradora docente PPGDesign da ESDI-UERJ, vice-presidente da International Visual Literacy Association, EUA e co-editora da InfoDesign - Revista Brasileira de Design da Informação. Foi presidente da Sociedade Brasileira de Design da Informação nas gestões 20032005 e 2005-2007. Tem expertise em Design da Informação, atuando principalmente nos seguintes temas: design instrucional e linguagem gráfica.

cgspin@terra.com.br 